\title{
Percepções sobre a discriminação homofóbica entre concluintes do Ensino Médio no Brasil entre 2004 e 2008
}

\section{Perceptions about the homophobic discrimination among High School graduates in Brazil from 2004 to 2008}

\author{
Araci Asinelli-Luz ${ }^{1}$ \\ Josafá Moreira da Cunha ${ }^{2}$
}

\begin{abstract}
RESUMO
A discriminação homofóbica no contexto escolar é um problema grave em vários níveis de ensino, e está associada negativamente à percepção dos estudantes sobre o ambiente escolar. O presente estudo utiliza dados de 6.414.302 estudantes com idade entre 16 e 25 anos disponíveis no questionário sócioeconômico do Exame Nacional do Ensino Médio entre 2004 e 2008. São apresentados dados sobre a incidência de três fatores associados à homofobia entre concluintes do ensino médio: (1) sofrer discriminação homofóbica, (2) presenciar discriminação homofóbica e (3) admitir homofobia. A análise da associação entre a homofobia e a percepção dos estudantes sobre sua educação no ensino médio revela que os estudantes que não relatam ter sido alvos da discriminação homofóbica avaliam sua experiência escolar de forma mais positiva que seus pares que sofreram discriminação.

Palavras-chave: discriminação; homofobia; escola; ensino médio.
\end{abstract}

1 Doutora em Educação, professora do Programa de Pós-Graduação em Educação da Universidade Federal do Paraná (UFPR), membro do Conselho e do GT-Educação da Sociedade Brasileira para o Progresso da Ciência (SBPC) e do Comitê da Criança e do Adolescente da OABPR. Pós-doutoranda em Educação.

2 Psicólogo, Mestre e doutorando em Educação junto ao Programa de Pós-Graduação em Educação da Universidade Federal do Paraná (UFPR). Bolsista de Pesquisa pelo Conselho Nacional de Desenvolvimento Científico e Tecnológico (CNPq). 


\begin{abstract}
Homophobic discrimination as a school matter is a serious problem, and is negatively associated with students' perception about the school environment. The present study uses data of $6,414,302$ students, aged between 16 and 25, available from the socioeconomic questionnaire of the National Examination of High School in Brazil (ENEM) between 2004 and 2008. A data regarding the incidence of three factors related to homophobia among these students is presented: (1) suffering homophobic discrimination, (2) witnessing homophobic discrimination and (3) admitting homophobia. The analysis of the relationship between homophobia and the perception of students regarding their high school education shows that students who did not report having been the targets of homophobic discrimination evaluate their school experience more positively than their peers who have experienced discrimination.
\end{abstract}

Keywords: discrimination; homophobia; school; high school.

\title{
Introdução
}

Os estudos sobre as violências em geral e, em particular, as que encontram na escola o espaço adequado para sua manifestação, ganham destaque por sua complexidade exigindo respostas no campo das políticas públicas de educação, saúde, segurança pública, direitos humanos e ação social, prioritariamente. A escola ainda se mantém, depois da família, como o núcleo mais importante de socialização e desenvolvimento humano onde a diversidade humana coloca em ação as mais diversas formas de relações sociais balizadas pela cultura, valores, princípios éticos, morais, espirituais, modelo de gestão escolar, níveis de tolerância e respeito entre as pessoas.

Os episódios de agressão interpessoal que ocorrem no espaço escolar, a despeito de sua forma de manifestação (ex.: agressão física, verbal, exclusão), podem ser compreendidos por meio de fatores como, por exemplo, a etnia dos participantes, que são usados como motivo ou justificativa para violar direitos de pessoas que apresentam características ou comportamentos considerados desviantes. Dentre essas diferentes formas de discriminação, ressalta-se o preconceito por orientação sexual e identidade de gênero, genericamente conhecidos como homofobia, que tem recebido atenção crescente na sociedade brasileira em anos recentes.

Entende-se que a escola na atualidade tem como uma de suas funções 
educar para a diversidade, desconstruindo-se como espaço cultural de perpetuação da heterossexualidade como única manifestação possível da sexualidade humana. Este artigo é dedicado à reflexão sobre os desafios enfrentados pela escola enquanto espaço ecológico de desenvolvimento humano que possibilita a compreensão dos diferentes tipos de relações afetivas.

\section{Homofobia: um conceito e muitas implicações}

A ausência da Educação Sexual enquanto política pública no campo da educação brasileira, mascarada por inserções pontuais em tempos de crise, acaba por firmar as dificuldades sentidas por gestores, professores, assessores, pedagogos, comunidade, em trazer para o espaço pedagógico o que a cultura social procura manter circunscrito no espaço privado da família e da moral: a sexualidade humana, para além de sua dimensão biológica.

O movimento internacional sobre Direitos Humanos, as feministas e as comunidades de lésbicas, gays, homossexuais, bissexuais, travestis, transgêneros, apontaram a nova pauta de saberes que deve circular na família, na escola, na sociedade e, por conseguinte, na instância das políticas públicas de educação, saúde, segurança pública e cidadania Diferente de outros movimentos de reivindicação de igualdade de direitos, ainda hoje, "os homossexuais lutam pelo direito à vida, ao respeito, à dignidade" (DIGNIDADE, 2008, p. 12), direitos que lhes são negados "devido sua orientação sexual ou identidade de gênero". $\mathrm{Na}$ década de 1990, entre os temas transversais que complementam os Parâmetros Curriculares Nacionais (BRASIL, 1998), a sexualidade ganhou status, mesmo que ainda com enfoque utilitarista e de controle do corpo enquanto possibilidade de prazer.

É nesse contexto de construção de cidadania que a temática da sexualidade revela a ruptura da hegemonia da heterossexualidade como única forma de relação afetiva entre homens e mulheres.

A homossexualidade, juntamente com a prática e a vivência heterossexual e a bissexualidade, constitui o que se define como a orientação sexual de cada pessoa, ou seja, o desejo sexual, aqui relativizado como as muitas possibilidades do prazer. Assim, ORIENTAÇÃO SEXUAL não é o mesmo que PRÁTICA SEXUAL (aquilo que as pessoas fazem no sexo), nem do que IDENTIDADE SEXUAL (como as pessoas se sentem ou são nominadas a partir de suas práticas sexuais). (FURLANI, 2007, p. 154). 
Para Smigay (2002, p. 34), "homofobia ainda é um conceito ambíguo, geralmente associado à homossexualidade, uma postura de rejeição, de medo de contato", enquanto Abramovay, Castro e Silva (2004) referem-se à homofobia enquanto "tratamento preconceituoso e às discriminações sofridas por jovens tidos como homossexuais, ferindo a dignidade alheia e gerando sofrimentos e revoltas".

A homofobia, portanto, reflete a aversão, o ódio, sentimento de repulsa ou medo que é sentido e/ou manifestado por pessoas e que resulta em atitude de hostilidade e violências em relação à pessoa homossexual, caracterizando uma manifestação arbitrária que qualifica o homossexual como contrário, inferior, anormal, estranho e, por isso, o discrimina e agride. Sua magnitude, enquanto violação dos direitos humanos universais resultou em 2004, na criação do Programa Brasil sem Homofobia: programa de combate à violência e à discriminação contra lésbicas, gays, bissexuais e transexuais - LGBT e de promoção da cidadania homossexual (BRASIL, 2008), responsável pela articulação de instituições públicas, privadas e do terceiro setor, bem como pessoas, especialistas e movimentos sociais no planejamento e execução de políticas afirmativas em prol da "escola sem homofobia".

Igualmente, em novembro de 2006, em Yogyakarta, na Indonésia, especialistas de 25 países $^{3}$, a partir de trabalho da Comissão Internacional de Juristas e do Serviço Internacional de Direitos Humanos, adotaram "Os Princípios de Yogyakarta" como o espectro de normas de direitos humanos a serem implementadas pelos Estados às questões de orientação sexual e identidade de gênero.

A compreensão da orientação sexual e da identidade de gênero permite ressaltar que alguns grupos, por sua visibilidade, podem despertar maior intolerância se comparados a outro em uma determinada sociedade, determinando que os mecanismos da homofobia possam ser diferentes para as diversas orientações sexuais e identidades de gênero. Assim é que a Associação Brasileira de Gays, Lésbicas, Travestis e Transexuais - ABGLT estimula a utilização dos conceitos em suas especificidades, auxiliando na compreensão do fenômeno e no aprimoramento das informações.

- Homofobia internalizada: refere-se ao medo de ver sua orientação sexual revelada publicamente, levando o indivíduo a adotar atitudes preconceituosas contra LGBT.

- Lesbofobia: palavra criada para representar a rejeição e/ou aversão às lésbicas

3 O Brasil foi representado por Sonia Onufer Corrêa, pesquisadora associada da Associação Brasileira Interdisciplinar de AIDS (ABIA) e coordenadora do Observatório de Sexualidade e Política. 
- Transfobia: palavra criada para representar a rejeição e/ou aversão às transexuais.

A homofobia, como se pode perceber, é um assunto complexo e, na sua relação com a escola, "envolve inclusão/exclusão, educação para a sexualidade, orientação sexual, identidade sexual, estudos sobre gênero e homossexualidade" (KOEHLER, 2009, p. 590) e, especialmente, a formação adequada de professores para educar para a diversidade como forma de enfrentar o preconceito e a discriminação homofóbica, contribuindo para a escola sem homofobia.

Ao examinar a literatura sobre a incidência da discriminação homofóbica em escolas brasileiras na última década, destaca-se a Pesquisa Nacional Violência, Aids e Drogas nas Escolas, cuja coleta de dados foi conduzida em 2001, com a participação de 16.422 estudantes do ensino fundamental e médio em quatorze capitais brasileiras (ABRAMOVAY; CASTRO; SILVA, 2004). Os resultados indicaram que aproximadamente um quarto dos estudantes que participaram daquele estudo (27\%) não gostariam de conviver com homossexuais em suas salas de aula, sendo que este percentual foi mais elevado entre os participantes do sexo masculino do que entre as participantes do sexo feminino (respectivamente $39,4 \%$ e 16,5 ).

O trabalho de Abramovay, Cunha e Calaf (2009) apresenta dados sobre 9.937 estudantes do ensino fundamental e médio no Distrito Federal em 2008. Naquele ano letivo, $63,1 \%$ dos estudantes que participaram da pesquisa relataram ter observado episódios de discriminação homofóbica e 27,8\% dos estudantes não gostariam de ter colegas de classe homossexuais. Nota-se que na variável referente a preferir manter-se socialmente distante de pessoas homossexuais identificou-se uma diferença acentuada ao comparar-se os participantes por sexo, sendo que $44,4 \%$ entre os homens responderam afirmativamente (ou seja, não gostariam de ter colegas de classe homossexuais) comparado a $14,9 \%$ entre as mulheres.

A Pesquisa Sobre Ações Discriminatórias no Âmbito Escolar (MAZZON, 2009), planejada a partir do Censo Escolar de 2007, inclui dados sobre 15.087 estudantes do ensino fundamental regular (EFR), ensino médio regular (EMR) e da educação de jovens e adultos (EJA), além de diretores, professores, funcionários, pais e mães de alunos. Os resultados deste estudo indicam que um percentual elevado de estudantes presenciou ou soube de episódios em que algum estudante foi humilhado $(35,6 \%)$ ou agredido fisicamente $(18,7 \%)$ dentro do espaço escolar por ser homossexual. Este estudo tem especial importância por seu delineamento, que permite uma estimativa mais adequada sobre a incidência da discriminação homofóbica em escolas brasileiras.

Análise de dados e conhecimento dos desafios 
Apresenta-se a seguir uma análise quantitativa, a partir de dados do Exame Nacional do Ensino Médio (ENEM) entre os anos de 2004 e 2008 publicados pelo Instituto Nacional de Estudos e Pesquisas Educacionais, visando descrever a incidência da homofobia entre concluintes do Ensino Médio neste período. A análise inclui a comparação em relação ao sexo e localização (Unidade da Federação) dos participantes. Além disso, compara-se a percepção dos participantes que sofreram ou não discriminação homofóbica quanto à educação recebida no ensino médio. $\mathrm{O}$ delineamento utilizado é descrito a seguir.

\section{O Exame Nacional do Ensino Médio (ENEM)}

O ENEM, implementado a partir de 1998 como um teste de avaliação do desempenho de estudantes concluintes do Ensino Médio em todo o Brasil, representa um marco importante na avaliação da educação brasileira. Os dados incluem o desempenho individual dos participantes na prova objetiva e de redação e, além disso, dados detalhados sobre os participantes coletados através de um questionário sócio-demográfico. É importante destacar que, por constituirse como exame de adesão voluntária, esta base de dados tem um possível viés quanto a auto-seleção dos participantes.

Para o presente estudo foram selecionados apenas os estudantes que atendessem aos seguintes critérios: (1) faixa etária entre 16 e 25 anos (concentra $90 \%$ dos concluintes do ensino regular no período estudado) e (2) ano de conclusão do Ensino Médio (foram incluídos apenas aqueles que declararam estar concluindo o ensino médio no mesmo ano de realização do ENEM). Após a filtragem dos participantes a partir dos critérios expostos, a amostra que originalmente continha dados sobre 15.902.824 estudantes foi reduzida para 6.414.302 estudantes, sendo que um sumário da amostra utilizada é apresentado na Tabela 1.

TABELA 1 - SUMÁRIO DESCRITIVO DA AMOSTRA DE ESTUDANTES SELECIONADA

\begin{tabular}{c|c|c|c|c|c}
\hline \multirow{2}{*}{ Ano ENEM } & \multirow{2}{*}{$\mathrm{N}$} & \multicolumn{2}{|c|}{ Idade } & \multicolumn{2}{c}{ Sexo } \\
\cline { 3 - 6 } & & Média & d.p*. & \% Masculino & \% Feminino \\
\hline 2004 & 1.101 .611 & 18,3 & 1,7 & 40,0 & 60,0 \\
2005 & 1.370 .749 & 18,5 & 1,9 & 40,5 & 59,5 \\
2006 & 1.433 .125 & 18,4 & 1,8 & 40,6 & 59,4 \\
2007 & 1.139 .635 & 18,2 & 1,6 & 39,6 & 60,4 \\
2008 & 1.369 .182 & 18,2 & 1,7 & 39,8 & 60,2 \\
Total & 6.414 .302 & 18,3 & 1,8 & 40,1 & 59,9 \\
\hline
\end{tabular}

* d.p corresponde ao desvio padrão. 
Os dados sistematizados nessa tabela mostram a idade média dos estudantes em torno dos 18 anos e um N maior no ano de 2006, bem como maior participação de estudantes do sexo feminino durante todo o período a que se refere essa pesquisa.

\section{Medidas}

\section{Variáveis Demográficas}

A variável sexo (TP_SEXO) foi utilizada sem alteração na codificação descrita no dicionário de variáveis do ENEM ( 1 = masculino; 2 = feminino). $\mathrm{O}$ cálculo da idade dos participantes foi efetuado a partir dos quatro dígitos do ano contidos na variável data de nascimento (DT_ NASCIMENTO), sendo selecionados apenas aqueles que atendessem o critério etário descrito anteriormente (16 anos $\leq$ Idade no Ano ENEM $\leq 25$ anos).

\section{Homofobia}

O questionário sociodemográfico nos anos estudados inclui uma seção em que os participantes relatam experiências de discriminação, sendo que os itens relacionados à discriminação homofóbica foram selecionados, permitindo avaliar a percepção dos participantes a respeito de três aspectos da homofobia. O primeiro, avaliado pelo item "Você já sofreu discriminação por ser (ou parecer ser) homossexual" permitiu examinar qual parcela da amostra estudada sofreu alguma forma de discriminação homofóbica. O segundo item, "Você já presenciou discriminação contra homossexuais", permitiu avaliar em que medida os participantes atribuíram eventos de discriminação que observaram à homofobia. No terceiro item, "Você se incomodaria se tivesse como parente ou colega de escola ou de trabalho uma pessoa homossexual" foi possível verificar qual parcela da amostra admitiu a homofobia no que diz respeito a preferir manter-se socialmente distante de pessoas homossexuais. Em cada um destes indicadores os participantes poderiam responder sim ou não, sendo que o terceiro item (incomodar-se com homossexuais) estava disponível apenas a partir da edição 2005 do ENEM. 


\section{Percepção da escola no Ensino Médio}

Selecionou-se um ítem apenas, "Que nota você daria para a formação que você obteve no ensino médio?”, como indicador da percepção geral dos participantes sobre sua experiência escolar, variando de 0 a 10.

\section{Resultados}

\section{Incidência da homofobia}

Ao analisar a prevalência de participantes que declararam ter sido alvo de discriminação por serem ou parecerem ser homossexuais (Tabela 2), verificou-se a menor incidência entre os participantes do ENEM 2004, enquanto que entre as edições 2005 e 2008 não foram verificadas variações expressivas no percentual total de participantes que sofreram homofobia. Ao avaliar a prevalência neste período por sexo dos participantes, utilizando o teste do qui-quadrado $\left(\chi^{2}\right)$ para a comparação de proporções, verificou-se que a prevalência da discriminação homofóbica entre os participantes do sexo masculino foi significativamente mais alta que a verificada entre as participantes do sexo feminino, sendo que a razão entre a prevalência por sexo variou de 0,65 (ENEM 2004) a 0,54 (ENEM 2008) no período estudado.

TABELA 2 - PERCENTUAL DE PARTICIPANTES QUE SOFRERAM DISCRIMINAÇÃO HOMOFÓBICA

\begin{tabular}{|c|c|c|c|c|}
\hline \multirow{3}{*}{ Ano ENEM } & \multicolumn{3}{|c|}{ Sofrer $(\%)$} & \multirow{3}{*}{$\chi^{2}$ (g.l.) } \\
\hline & \multirow{2}{*}{ Total } & \multicolumn{2}{|c|}{ Sexo } & \\
\hline & & Masculino & Feminino & \\
\hline 2004 & 1,6 & 2,0 & 1,3 & $465,2 *(1)$ \\
\hline 2005 & 3,7 & 5,1 & 2,8 & $3137,8 *(1)$ \\
\hline 2006 & 3,8 & 5,1 & 2,9 & $3026,4 *(1)$ \\
\hline 2007 & 3,8 & 5,3 & 2,9 & $3180,4^{*}(1)$ \\
\hline 2008 & 4,0 & 5,6 & 3,0 & $3811,6^{*}(1)$ \\
\hline
\end{tabular}

Nota: $* \mathrm{p}<0,001$. 
Ao examinar o percentual de participantes que relataram ter presenciado episódios de discriminação homofóbica, verificou-se o aumento acentuado no período entre 2004 e 2006, quando o percentual de participantes que presenciaram atos de discriminação homofóbica aumentou em 9,7\%. Já nos dois anos subsequentes, no período entre 2006 e 2008 verificou-se a tendência de queda nesse percentual, que diminuiu $2,5 \%$. Ao comparar esta variável em função do sexo dos participantes, verificou-se que o percentual significativamente mais elevado de participantes do sexo feminino relatou ter observado episódios de discriminação homofóbica.

TABELA 3 - PERCENTUAL DE PARTICIPANTES QUE PRESENCIARAM DISCRIMINAÇÃO HOMOFÓBICA

\begin{tabular}{c|c|c|c|c}
\hline \multirow{2}{*}{ Ano ENEM } & \multicolumn{3}{|c|}{ Presenciar (\%) } & \multirow{2}{*}{$\chi^{2}$ (g.1.) } \\
\cline { 2 - 4 } & \multirow{2}{*}{ Total } & \multicolumn{2}{|c}{ Sexo } & \\
\cline { 3 - 4 } & & \multicolumn{2}{|c}{ Feminino } & $1635,0^{*}(1)$ \\
\cline { 3 - 4 } 2004 & 56,4 & 53,5 & 58,3 & $1775,9^{*}(1)$ \\
2005 & 64,2 & 61,6 & 65,9 & $1949,2^{*}(1)$ \\
2007 & 66,1 & 63,5 & 67,8 & $1430,3^{*}(1)$ \\
2008 & 64,3 & 61,9 & 65,8 & $1630,0^{*}(1)$ \\
\hline
\end{tabular}

Nota: ${ }^{p} p<0,001$.

Na questão sobre "incomodar-se caso tivesse parentes ou colegas homossexuais", que estava disponível apenas nas edições a partir do ENEM 2005, identificou-se o decréscimo expressivo no percentual de participantes que preferiam manter-se distantes socialmente de pessoas homossexuais no período entre 2005 e 2007, sendo que no período entre 2007 e 2008 houve um pequeno aumento neste percentual $(+0,3 \%)$. Ao analisar os dados desta variável por sexo dos participantes verificou-se que em todos os anos incluídos neste estudo o percentual de participantes do sexo masculino que admitia preferir manterse distante de homossexuais foi mais que três vezes superior ao percentual de mulheres que se sentiriam incomodadas caso tivessem um parente ou colega homossexual. 
TABELA 4 - PERCENTUAL DE PARTICIPANTES QUE SE SENTIRIAM INCOMODADOS POR TER PARENTE OU COLEGA HOMOSSEXUAL (ADMITIR HOMOFOBIA)

\begin{tabular}{c|c|c|c|c}
\hline \multirow{2}{*}{ Ano ENEM } & \multicolumn{3}{|c|}{ Admitir (\%) } & \multirow{2}{*}{$\chi^{2}$ (g.1.) } \\
\cline { 2 - 4 } & \multirow{2}{*}{ Total } & \multicolumn{2}{|c|}{ Sexo } & \\
\cline { 3 - 4 } & & \multicolumn{2}{|c}{ Feminino } & $33619,2^{*}(1)$ \\
2005 & 9,7 & 16,9 & 5,1 & $33873,5^{*}(1)$ \\
2006 & 8,6 & 15,0 & 4,4 & $25007,0^{*}(1)$ \\
2008 & 6,9 & 12,2 & 3,5 & $26142,0^{*}(1)$ \\
\hline
\end{tabular}

Nota: ${ }^{*} \mathrm{p}<0,001$.

Considerando a diversidade de cenários em relação ao combate e até mesmo apologia à homofobia que são observados no contexto brasileiro, procedeuse uma análise sobre a prevalência dos três indicadores da homofobia em cada unidade da federação no período estudado (Quadro 1). Em uma primeira análise sobre a incidência de participantes que sofreram discriminação homofóbica, verifica-se uma grande variabilidade, que vai de $0,9 \%$ (Santa Catarina, ENEM 2004) a $6,7 \%$ (Roraima, 2005). No entanto, ao considerar a mudança neste índice no período de 2005 a 2008, verifica-se que enquanto em Santa Catarina o índice permaneceu estável entre 2,7 e $2,8 \%$ a partir de 2005 , foi verificado um decréscimo expressivo no mesmo período entre os concluintes do ensino médio em Roraima.

QUADRO 1 - DESCRIÇÃO DOS INDICADORES DA HOMOFOBIA POR UNIDADE DA FEDERAÇÃO

(continua)

\begin{tabular}{|c|c|c|c|c|c|c|c|c|c|c|c|c|c|c|}
\hline & \multicolumn{5}{|c|}{$\begin{array}{c}\text { Sofreu homofobia } \\
(\% \text { Ano })\end{array}$} & \multicolumn{5}{|c|}{$\begin{array}{l}\text { Observou homofobia } \\
(\% \text { Ano })\end{array}$} & \multicolumn{4}{|c|}{$\begin{array}{l}\text { Admitiu homofobia } \\
(\% \text { Ano })\end{array}$} \\
\hline & 2004 & 2005 & 2006 & 2007 & 2008 & 2004 & 2005 & 2006 & 2007 & 2008 & 2005 & 2006 & 2007 & 2008 \\
\hline \multicolumn{15}{|c|}{ Região Centro-Oeste } \\
\hline MS & 1,7 & 3,4 & 3,6 & 4,0 & 4,0 & 53,9 & 63,6 & 64,7 & 64,4 & 63,1 & 10,5 & 9,5 & 7,4 & 8,5 \\
\hline MT & 1,9 & 3,8 & 3,8 & 4,0 & 4,5 & 58,3 & 66,5 & 68,0 & 64,9 & 65,4 & 10,3 & 9,6 & 8,2 & 8,8 \\
\hline $\mathrm{DF}$ & 2,3 & 4,7 & 4,2 & 4,3 & 4,6 & 59,8 & 70,3 & 73,2 & 71,0 & 72,4 & 12,2 & 10,2 & 8,9 & 9,6 \\
\hline $\mathrm{GO}$ & 1,7 & 3,7 & 3,4 & 3,8 & 3,9 & 58,4 & 67,4 & 69,2 & 68,3 & 67,3 & 10,3 & 9,1 & 7,1 & 8,1 \\
\hline \multicolumn{15}{|c|}{ Região Nordeste } \\
\hline $\mathrm{AL}$ & 1,7 & 4,4 & 3,9 & 4,2 & 4,5 & 66,9 & 71,1 & 74,1 & 71,0 & 70,4 & 7,5 & 6,8 & 5,1 & 5,9 \\
\hline $\mathrm{BA}$ & 1,7 & 4,2 & 4,1 & 4,2 & 4,4 & 60,2 & 67,9 & 69,1 & 66,4 & 67,0 & 8,8 & 7,9 & 6,3 & 6,8 \\
\hline $\mathrm{CE}$ & 1,9 & 4,7 & 4,5 & 4,9 & 5,3 & 64,6 & 71,6 & 73,7 & 71,6 & 70,5 & 8,0 & 7,1 & 5,6 & 5,7 \\
\hline
\end{tabular}


QUADRO 1 - DESCRIÇÃO DOS INDICADORES DA HOMOFOBIA POR UNIDADE DA FEDERAÇÃO (conclusão)

\begin{tabular}{|c|c|c|c|c|c|c|c|c|c|c|c|c|c|c|}
\hline MA & 2,5 & 4,1 & 4,6 & 4,5 & 3,9 & 60,3 & 71,0 & 70,9 & 69,5 & 65,4 & 9,8 & 8,6 & 7,5 & 7,2 \\
\hline PB & 1,7 & 3,7 & 3,9 & 3,8 & 4,1 & 61,2 & 69,9 & 71,4 & 70,2 & 68,2 & 8,7 & 8,5 & 6,1 & 6,6 \\
\hline PE & 1,6 & 3,8 & 3,9 & 4,0 & 4,1 & 64,3 & 71,0 & 71,5 & 69,9 & 69,9 & 9,6 & 8,2 & 6,4 & 7,1 \\
\hline PI & 1,8 & 3,4 & 3,4 & 3,7 & 3,7 & 58,1 & 65,4 & 68,0 & 66,3 & 64,0 & 8,9 & 7,9 & 6,2 & 6,6 \\
\hline $\mathrm{RN}$ & 1,6 & 3,9 & 3,7 & 4,2 & 4,2 & 63,3 & 70,5 & 71,6 & 68,3 & 68,2 & 7,5 & 6,2 & 5,1 & 5,2 \\
\hline $\mathrm{SE}$ & 2,4 & 4,1 & 3,9 & 4,1 & 4,1 & 64,8 & 69,7 & 72,5 & 70,2 & 69,6 & 6,9 & 5,4 & 4,7 & 5,2 \\
\hline \multicolumn{15}{|c|}{ Região Norte } \\
\hline $\mathrm{AC}$ & 2,4 & 6,3 & 6,2 & 5,5 & 5,4 & 61,9 & 67,7 & 70,6 & 68,1 & 68,5 & 8,7 & 8,8 & 6,5 & 6,9 \\
\hline $\mathrm{AM}$ & 2,9 & 5,1 & 5,3 & 5,2 & 6,1 & 63,2 & 68,8 & 72,0 & 69,8 & 68,8 & 9,0 & 8,0 & 6,7 & 7,1 \\
\hline $\mathrm{AP}$ & 2,6 & 6,1 & 5,8 & 6,4 & 6,4 & 69,1 & 75,6 & 77,7 & 78,0 & 76,1 & 9,7 & 8,4 & 7,1 & 7,0 \\
\hline $\mathrm{PA}$ & 2,4 & 4,8 & 5,2 & 4,9 & 5,5 & 63,8 & 72,0 & 74,1 & 72,8 & 72,6 & 9,0 & 7,7 & 6,5 & 7,1 \\
\hline RO & 1,6 & 3,6 & 4,1 & 4,1 & 4,0 & 56,4 & 64,2 & 66,1 & 64,2 & 62,1 & 10,3 & 8,4 & 7,2 & 7,3 \\
\hline $\mathrm{RR}$ & 2,3 & 6,7 & 5,4 & 4,8 & 4,4 & 63,8 & 69,5 & 72,4 & 69,8 & 68,1 & 10,0 & 10,4 & 8,0 & 9,2 \\
\hline TO & 2,4 & 4,0 & 4,1 & 4,2 & 4,1 & 55,4 & 62,5 & 67,0 & 63,7 & 64,1 & 12,3 & 10,5 & 9,3 & 8,3 \\
\hline \multicolumn{15}{|c|}{ Região Sudeste } \\
\hline ES & 1,5 & 3,5 & 3,7 & 3,6 & 3,7 & 59,6 & 69,0 & 69,8 & 66,6 & 65,1 & 11,9 & 11,4 & 8,8 & 8,6 \\
\hline MG & 1,4 & 3,1 & 3,3 & 3,1 & 3,4 & 56,0 & 64,1 & 66,2 & 63,6 & 63,9 & 9,0 & 8,0 & 6,0 & 6,7 \\
\hline RJ & 1,8 & 4,0 & 4,1 & 4,1 & 4,4 & 56,6 & 64,8 & 66,1 & 64,3 & 63,6 & 9,3 & 8,3 & 6,6 & 7,3 \\
\hline $\mathrm{SP}$ & 1,5 & 3,7 & 3,9 & 3,9 & 3,9 & 55,0 & 60,9 & 62,3 & 61,7 & 60,9 & 9,5 & 8,5 & 6,8 & 6,9 \\
\hline \multicolumn{15}{|c|}{ Região Sul } \\
\hline PR & 1,2 & 2,8 & 3,0 & 3,0 & 3,3 & 47,9 & 58,6 & 60,8 & 59,2 & 58,5 & 13,5 & 11,6 & 9,4 & 9,4 \\
\hline RS & 1,1 & 2,5 & 2,4 & 2,5 & 2,7 & 47,1 & 58,8 & 58,3 & 56,5 & 56,9 & 9,3 & 7,8 & 6,1 & 6,5 \\
\hline $\mathrm{SC}$ & 0,9 & 2,8 & 2,7 & 2,7 & 2,8 & 45,8 & 57,4 & 57,6 & 57,3 & 56,8 & 12,3 & 10,9 & 8,2 & 8,1 \\
\hline
\end{tabular}

O percentual de participantes que observaram episódios de discriminação homofóbica variou de 45,8\% (Santa Catarina, ENEM 2004) a 78\% (Amapá, ENEM 2007). O valor elevado destes índices de prevalência sugere que a discriminação contra homossexuais parece ser uma ocorrência banalizada e corriqueira nos contextos sociais em que estes estudantes estavam inseridos.

A seguir, avaliando qual percentual dentre os participantes concluintes do ensino médio entre 2005 e 2008 admitiram que se sentiriam incomodados caso tivessem parentes ou colegas homossexuais, foram verificados valores de prevalência entre 13,5\% (Paraná, ENEM 2005), e 4,7\% (Sergipe, ENEM 2007). Ao avaliar as tendências de mudança neste indicador no período estudado, verificou-se em alguns estados um decréscimo continuado neste indicador durante todo o período estudado (ex., Tocantins), enquanto que para outros estados houve um decréscimo entre 2005 e 2007, e estabilização (ex., Paraná) ou aumento (ex., Rio de Janeiro) em 2008. 


\section{Consequências da discriminação}

Ao comparar as médias dos participantes no que diz respeito a suas percepções sobre a qualidade da educação que receberam no ensino médio, avaliada por meio de uma escala de dez pontos, foram verificadas diferenças estatisticamente significativas entre aqueles que relataram ter sofrido ou não discriminação homofóbica (Tabela 5). Em média, os participantes que sofreram discriminação homofóbica avaliaram a educação recebida no ensino médio aproximadamente meio ponto a menos que seus pares que não relatam essa experiência.

TABELA 5 - HOMOFOBIA E PERCEPÇÃO DA QUALIDADE DA EDUCAÇÃO RECEBIDA NO ENSINO MÉDIO

\begin{tabular}{c|c|c|c|c}
\hline & \multicolumn{2}{|c|}{$\begin{array}{c}\text { Avaliação da educação recebida no } \\
\text { Ensino Médio }\end{array}$} & (cofreu \\
\hline Ano ENEM & $\begin{array}{c}\text { Não sofreu } \\
\text { homofobia }\end{array}$ & $\begin{array}{c}\text { Diferença } \\
\text { momofobia }\end{array}$ & t \\
\hline 2004 & 7,18 & 6,38 & $0,79^{* *}$ & 34,28 \\
2005 & 7,31 & 6,72 & $0,59^{* *}$ & 50,42 \\
2006 & 7,32 & 6,80 & $0,52^{* *}$ & 46,30 \\
2007 & 7,38 & 6,85 & $0,53^{* *}$ & 47,03 \\
2008 & 7,38 & 6,81 & $0,57^{* *}$ & 52,10 \\
Total & 7,32 & 6,76 & $0,56^{* *}$ & 100,61 \\
\hline
\end{tabular}

Nota: $* * \mathrm{p}<0,001 ; \mathrm{t}$ corresponde ao teste $\mathrm{t}$ de Student

\section{Considerações finais}

Os resultados sugerem percentuais elevados de estudantes, em particular do sexo masculino, que relatam discriminação por serem ou parecerem homossexuais. Essa diferença entre os participantes do sexo masculino e feminino pode estar associada à intolerância maior em relação à homossexualidade masculina, sendo ainda plausível que o termo "homossexual", utilizado no questionário socioeconômico do ENEM tenha sido interpretado pelos participantes como 
específico da homossexualidade masculina.

A análise dos indicadores da discriminação homofóbica no período entre 2004 e 2008, destaca a queda abrupta no percentual de estudantes que relataram ter sofrido ou presenciado a discriminação homofóbica ao contrastar as coortes de concluintes em 2004 e 2005. É interessante notar que no ano de 2004 foi lançado no Brasil um programa federal de combate à violência e discriminação contra LGBT, Programa Brasil sem Homofobia, cuja implementação possibilitou o acesso a informações sobre a homofobia. Assim sendo, esta mudança pode indicar um decréscimo na invisibilidade da homofobia a partir do estímulo de ações de promoção dos direitos humanos. Note-se, porém, que não foi possível verificar se esta mudança ocorre também quanto ao percentual de concluintes que afirmam que se sentiriam incomodados ao conviver com homossexuais, já que esta variável não foi coletada no questionário do ENEM 2004.

O envolvimento individual na discriminação homofóbica pode ocorrer de diferentes formas, e a descrição aqui apresentada aborda três aspectos desta participação: (a) os alvos, (b) os expectadores e (c) aqueles que preferem manterem-se distantes de homossexuais. Os dados disponíveis não permitem identificar qual percentual dentre estes estudantes havia perpetrado atos agressivos com motivação homofóbica, que comporia uma categoria relevante de envolvimento na discriminação (perpetradores).

Em uma sociedade democrática, espera-se que estudantes sejam expostos a contextos de relacionamento onde a diversidade e o respeito pelas diferenças sejam valorizados. $\mathrm{O}$ combate à homofobia no contexto escolar traz benefícios não só para a população LGBT, mas contribui expressivamente para a melhoria do clima escolar.

Nogueira, Saavedra e Costa (2008, p. 61) propõem a visibilidade de gênero na escola como garantia do sentimento de pertencimento e reconhecimento entre "iguais" e "diferentes" ao afirmarem "perceber como o gênero (uma das muitas categorias de pertença) actua no nível da sexualidade em particular e se (re) produz no quotidiano escolar (FRANCIS, 2000) é fundamental para melhor equacionar projectos educativos"(sic).

As questões de gênero perceptíveis nos dados de análise decorrentes do ENEM (percepção da homofobia, ser alvo ou vítima de discriminação, incomodar-se com a presença de colegas homossexuais, entre outros) reforçam o que as autoras acima citadas afirmam para quebrar o status quo da desigualdade e discriminação homofóbica e de gênero na escola: "Todos os agentes educativos devem ter conhecimento da influência de gênero, reflectir sobre as suas práticas

4 FRANCIS, B. Boys, girls and achievement: addressing the classroom issues. London: Routledge, 2000. 
educativas e sobre o modo como estas ajudam a manter ou, pelo contrário, a desconstruir os discursos dominantes sobre a sexualidade (PAECHTER, 2006) . Só por meio dessa reflexão será possível resistir aos discursos reguladores e aderir a um projecto mais emancipador" (sic). Esta concepção deve ser estendida também para as diferentes orientações sexuais, possibilitando a melhor "compreensão do desequilíbrio de poder nas relações entre homens e mulheres e as suas conseqüências em termos de comportamentos sexuais (de vivência do desejo e do prazer, mas também dos comportamentos de risco)" (NOGUEIRA; SAAVEDRA; COSTA, 2008, p. 61).

A comparação dos dados nos diferentes níveis de agregação disponíveis na base do ENEM (ex.: rede de ensino, município, estado) tem grande potencial para subsidiar o acompanhamento de ações visando reduzir a discriminação. Embora avaliações sobre intervenções pontuais sejam importantes para orientar o desenvolvimento de estratégias de intervenção baseadas em evidências, é relevante monitorar indicadores como estes disponíveis na base de dados do ENEM, pois a melhoria da qualidade das escolas brasileiras não deve concentrar-se somente na mudança positiva dos indicadores de desempenho acadêmico, mas também na redução da discriminação sofrida por determinados grupos.

Embora o número de casos utilizados para realizar este estudo seja elevado, destaca-se que os dados estão restritos a estudantes que esperavam concluir o ensino médio e participaram do ENEM nos anos estudados. Considerando as elevadas taxas de abandono escolar verificadas nas escolas brasileiras, seria interessante conduzir estudos similares em outros níveis de ensino, examinando ainda a relação entre a discriminação homofóbica e outros indicadores de qualidade da educação.

De certa forma dados como esses, e sua visibilidade, acabam por facilitar medidas que diminuam a intolerância e a homofobia na escola, como a Portaria $\mathrm{n}^{\mathbf{o}}$ 233, de 18 de Maio de 2010, do Ministério de Estado do Planejamento, Orçamento e Gestão que, em consonância com a política de promoção e defesa dos direitos humanos, assegura "aos servidores públicos, no âmbito da Administração Pública Federal direta, autárquica e fundacional, o uso do nome social adotado por travestis e transexuais". Tal norma vem sendo adotada por Secretarias de Estado da Educação de diversos estados, garantindo o uso do nome social nas listas de chamada das escolas do ensino médio.

5 PAECHTER, C. Reconceptualizing the gendered body: learning and constructing masculinities and feminilities in school. Gender and Education, v. 18, p. 121-135, 2006. 


\section{REFERÊNCIAS}

ABRAMOVAY, M.; CASTRO, M. G.; SILVA, L. B. da. Juventude e sexualidade. Brasília: UNESCO, 2004.

ABRAMOVAY, M.; CUNHA, A. L.; CALAF, P. P. Revelando tramas, descobrindo segredos: violência e convivência nas escolas. Brasília: Rede de Informação Tecnológica Latino-americana, Secretaria de Estado de Educação do Distrito Federal, 2009.

BRASIL. Ministério da Educação, Instituto Nacional de Estudos e Pesquisas Educacionais. Microdados do Exame Nacional do Ensino Médio 2004: Manual do Usuário. Disponível em: <http://www.inep.gov.br/basica/levantamentos/microdados. asp>. Acesso em: 1/3/2010.

BRASIL. Ministério da Educação, Instituto Nacional de Estudos e Pesquisas Educacionais. Microdados do Exame Nacional do Ensino Médio 2005: Manual do Usuário. Disponível em: <http://www.inep.gov.br/basica/levantamentos/microdados. asp>. Acesso em: 1/3/2010.

BRASIL. Ministério da Educação, Instituto Nacional de Estudos e Pesquisas Educacionais. Microdados do Exame Nacional do Ensino Médio 2006: Manual do Usuário. Disponível em: <http:/www.inep.gov.br/basica/levantamentos/microdados. asp>. Acesso em: 1/3/2010.

BRASIL. Ministério da Educação, Instituto Nacional de Estudos e Pesquisas Educacionais. Microdados do Exame Nacional do Ensino Médio 2007: Manual do Usuário. Disponível em: <http://www.inep.gov.br/basica/levantamentos/microdados. asp>. Acesso em: 1/3/2010.

BRASIL. Ministério da Educação, Instituto Nacional de Estudos e Pesquisas Educacionais. Microdados do Exame Nacional do Ensino Médio 2008: Manual do Usuário. Disponível em: <http://www.inep.gov.br/basica/levantamentos/microdados. asp>. Acesso em: 1/3/2010.

BRASIL. Conselho Nacional de Combate à Discriminação. Brasil sem homofobia: programa de combate à violência e à discriminação contra GLBT e promoção da cidadania homossexual. Brasília: Secretaria Especial dos Direitos Humanos, 2008.

DIGNIDADE. Uma história de dignidade. Curitiba: Grupo Dignidade, 2008.

FURLANI, Jimena. Mitos e tabus da sexualidade humana: subsídios ao trabalho em educação sexual. 3 ed. Belo Horizonte: Autêntica, 2007. 
KOEHLER, S. M. F. A representação social da homofobia na cidade de Lorena/SP. Diálogo Educacional. Revista do Programa de Pós-Graduação Stricto Sensu em Educação, PUCPR, v. 9, n. 28, Curitiba, set./dez. 2009.

MARTINS, F. et al. (Orgs.). Manual de comunicação LGBT. Curitiba: Ajir, 2009.

MAZZON, J. A. Projeto de estudo sobre ações discriminatórias no âmbito escolar, organizadas de acordo com áreas temáticas, a saber, étnico racial, gênero, orientação sexual, geracional, territorial, de necessidades especiais e socioeconômica. São Paulo: Ministério da Educação, Instituto Nacional de Estudos e Pesquisas Educacionais, 2009. Disponível em: $<$ http://www.inep.gov.br/basica/levantamentos/microdados. asp>. Acesso em: 1/6/2010.

NOGUEIRA, C.; SAAVEDRA, L.; COSTA, C. (in)visibilidade do gênero na sexualidade juvenil: propostas para uma nova concepção sobre a educação sexual e a prevenção de comportamentos sexuais de risco. Pro-posições. Revista da Faculdade de Educação da Universidade Estadual de Campinas, v.19, n. 2 (56), maio/ago. 2008.

PRINCÍPIOS DE YOGYAKARTA. Princípios sobre a aplicação da legislação internacional de direitos humanos em relação à orientação sexual e identidade de gênero. Observatório de Sexualidade e Política, 2007 (www.yogyakartaprinciples.org).

SMIGAY, K.E. Sexismo, homofobia e outras expressões correlatas de violência: desafios para a psicologia política. Psicologia em Revista, Belo Horizonte, v. 8, n.11, p. 32-46, 2002.

Texto recebido em maio de 2010 .

Texto aprovado em outubro de 2010. 